\title{
Evaluation of genotype $\times$ environment relationship in silage maize genotypes using biplot analysis and stability index
}

\author{
Erkan Ozata (D) ${ }^{*}$ \\ ${ }^{1}$ Blacksea Agricultural Research Institute, Department of Field Crops, Samsun-Turkey
}

\begin{abstract}
This study was conducted to evaluate the adaptability and stability of silage maize hybrids determing herbage and dry matter yield using Biplot analysis and some stability indexes. The studies were carried out using five registered corn varieties under irrigated conditions for six years (2013-2018) in Çarşamba plain of Samsun province, Turkey. The experimental layout was a Randomized Complete Block Design with four replications. Finlay and Wilkenson's regression and Eberhart and Russel's deviation from regression $\left(\mathrm{S}^{2} \mathrm{~d}\right)$ coefficients were used in statistical analysis. Genotype $(G)$ x environment (E) interactions were studied using the additive main effects and multiplicative interaction (AMMI) and $G$ + GE (GGE) biplot models. The combined analysis of variance revealed significant $(P<0.01)$ effects of $G, E$ and $G \times E$ interaction on herbage and dry matter yields. The analysis of variance indicated that $62.70 \%$ of variation in the herbage yield explained by $\mathrm{E}$, $29.79 \%$ by the differences in $\mathrm{G}$ and $7.49 \%$ by the GE interaction. The analysis of variance indicated that $62.80 \%$ of the total variation in the dry matter yield accounted for $E$, $30.20 \%$ of the total variation by $\mathrm{G}$ and $\mathrm{G} \times \mathrm{E}$ interaction explained only $7.00 \%$ of the total variation in the data. The results of AMMI and GGE biplot models and stability analyses $\left(\mathrm{R}^{2}\right.$, bi and $S^{2}$ di) revealed that PR31Y43 and Burak hybrids were stable in both herbage yield and dry matter yield.
\end{abstract}

\section{ARTICLE HISTORY}

Received: 18 October 2020

Accepted: 05 December 2020

\section{KEYWORDS}

Dry matter yield

Herbage yield

GGE biplot

$\mathrm{G} \times \mathrm{E}$ interaction silage maize

Stability index

\section{* CORRESPONDING}

erkan.ozata@tarimorman.gov.tr

\section{Introduction}

Corn silage is an important nutrient source for ruminants; thus, widely used in the world and also produced nationwide in various climatic regions. High-quality corn silage is highly preffered for dairy farms and beef cattle producers due to the high energy value, easily digestible carbohydrate contains and convenience in storage for a long period of time.

Success in silage maize production depends on the accurate determination of the variety and implementation of necessary cultural practices on time. Different methods have been used to assess the adaptability and stability of cultivars employing the biometric analysis (Oliveria et al., 2019). Since genotype performance of a variety depends on several factors in different environments (Oliveria et al., 2019), analysis of genotype $(\mathrm{G}) \times$ environment (E) interaction (GE) is crucial for breeders and researchers conducting studies on different varieties under different environmental conditions. The responses of cultivated crops to changing climate or soil conditions have significant variations. Some cultivars may exhibit high GE, while the interaction in others may be very low. Quantitative and qualitative interactions may occur between cultivars and the environments (Dia et al. 2016; Parent et al., 2017; Gür and Kara, 2019). The variation in yield data reported in various environments (MET) are usually quite large. Understanding the general pattern of the data without a graphical presentation may not be possible. A genotype +GE (GGE) biplot, that has been first introduced by Yan (2001) based on data related to the environment, eliminates the environment main effect and considers the genotype as the main effect. Displaying the GGE of a MET data as a biplot allows to investigate and integrate $G$ and GE in determining superior genotypes in MET data analysis (Yan et al., 2001). Therefore, the Additive Main effects and Multiplicative Interaction (AMMI) and GGE biplot models are considered effective tools in cultivar evaluation and multi environment investigation in breeding programs (Yan et al., 2000; Samonte et al., 2005).

The AMMI and GGE biplot models have frequently been used for the analysis of multi-environment experiments to explain complexity of GE interaction, to idetify high yielding promising genotypes and to estimate adaptability of cultivars (Badu-Apraku et al., 2012). Therefore, the AMMI and GGE biplot models have become increasingly popular for agricultural researchers due to relavance to commonly encountered two-way data matrices (Naroui et al., 2013).

The GGE biplot analysis is based on environmentcentered principal component analysis (PCA), therefore 
explains more G+GE compared to the AMMI graph when many genotypes and test environments are involved. The environments in AMMI graph are labeled only along the $\mathrm{x}$ coordinate rather than across the graph, and the genotypes are indicated by the straight lines insted of dots (Yan et al., 2007). However, both analysis require a two-way data matrix, such as number of genotypes investigated in a number of environments. These analyses combine the analysis of variance (ANOVA) and PCA (Gauch, 2006). Visual evaluation of GE interaction pattern for multienvironmental data can be achieved better using the GGE biplot analysis. The crop yield in GGE biplot is assessed as the combined effect of G, E, and GE. In addition, the primary and secondary effects were identified under PC1 and PC2 in GGE biplot analysis. The PC's in GGE plots are derived from environment-centered yield data, therefore the genotypic response pattern across multi-environment can be visualized in a GGE biplot (Yan and Tinker, 2006).

Development of genotypes suitable for all environmental conditions, in other words, the least affected by the environmental variation, is one of main goals of the breeders. The ideal variety for a breeder has high yield potential and slihgt yield fluctuation in different environments. The main purpose of field expeirments conducted in multiple locations is to evaluate the adaptability of genotypes and to identify genotypes with promising yield potential for locations. The effects of environmental factors (irrigation, soil factors, abiotic and biotic stress factors etc.) on genotype, environment and genotypexenvironment interaction have been extensively studied and many methods have been proposed. Different stability indexes (bi, $\mathrm{S}^{2} \mathrm{~d}$, a constant, $\mathrm{r}^{2}$ ) and biplot models (G, GE, GEI and AMMI) have been used by breeders and researchers in different field crops for many years.

The aim of this study was to determine the most stable silage maize genotype/s evaluating herbage and dry matter yields using some stability indexes with AMMI and GGE biplot models.

\section{Materials and methods}

The yield stability of five different silage maize hybrids (Samada 07, Burak, PR37Y43, DKC7211 and DKC7221) was evaluated in a six-year field experiment (2013-2018) under irrigated conditions in Çarşamba town of Samsun city in Black Sea Region (4123’N, 36 50 'E) Turkey.

The soil of study area had clay loamy texture and was slightly alkaline. Total salt and available phosphorus contents were low, while rich in potassium content. Soil was slightly calcerous and low in organic matter content. The experiments were carried out in Samsun province which is characterized by a rainy and temperate climate. The relative humidity and temperature values in growing seasons during the experiment (2013-2018) were relatively close to each other, whereas differed from the long term averages. Average temperatures in 2014, 2015 and 2016 were $1-3{ }^{\circ} \mathrm{C}$ higher than the long term averages. Significant differences were measured in total precipitation and monthly precipitation values. The humidity values were lower than the long term values and the lowest humidity value was recorded in 2014 (Figure 1, 2 and 3).
The experimental layout was a Randomized Complete Block Design with four replications in each year. The seeds were sown in the beginning of the May by hand as placing two seeds in each seed bed. Each plot had four rows with 5 $m$ length and area of each experimental plot was $14 \mathrm{~m}^{2}$. The interrows spacing was $0.7 \mathrm{~m}$ and intra row was $0.18 \mathrm{~m}$. The lines were thinned removing the weak plants when the plants reached 4-6 leaf $(40-50 \mathrm{~cm})$. Fertilizer application rate, determined based on soil analyses, was $80 \mathrm{~kg} \mathrm{P}^{-1}$ and 220 $\mathrm{kg} \mathrm{N} \mathrm{ha}{ }^{-1}$. All phosphorus and $80 \mathrm{~kg} \mathrm{ha}^{-1}$ of nitrogen were applied at planting in bands, and the rest of the nitrogen was given at V4-V6 stage. The two middle lines of plots were harvested for green forage yield. The plants were harvested manually when kernel milk lines reached $1 / 2$ and 2/3 levels which is the early dough stage. Five hundred gram of plant samples was placed in an oven at $105^{\circ} \mathrm{C}$ for 48 hours until a constant weight attained. Dry matter yield values were calculated using the dry matter ratios of plants samples as follow;

Dry matter yield $(\mathrm{kg})=$ sample dry weight $(\mathrm{kg}) / \mathrm{sample}$ fresh weight (kg).

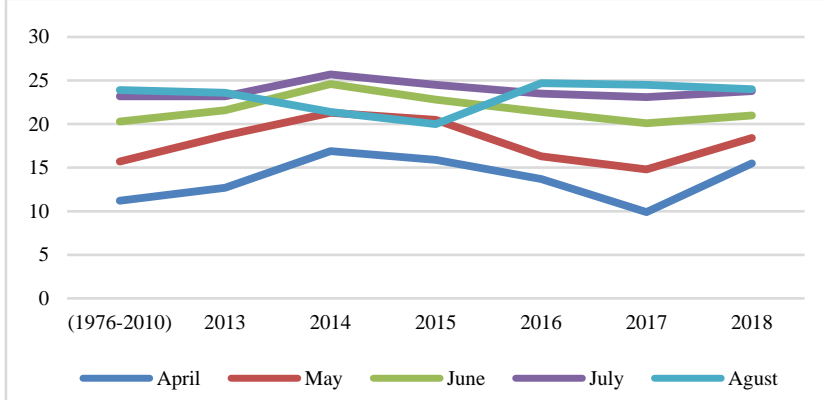

Figure 1. The mean temperature values $\left(\mathrm{C}^{\circ}\right)$ of the study area during maize growing seasons between 2013 and 2018.

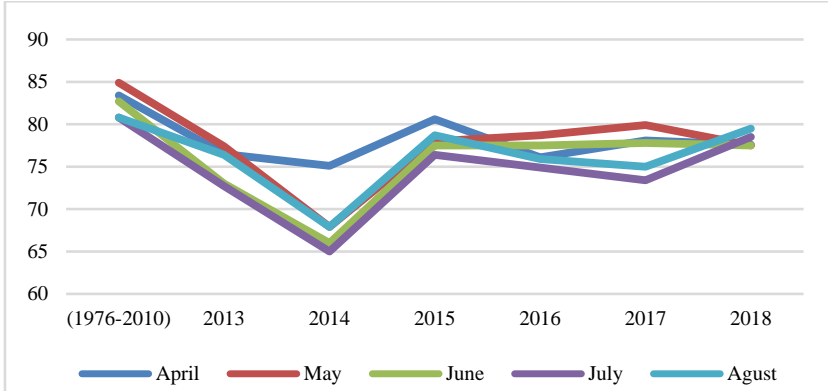

Figure 2. The mean humidity (\%) values of the study area during maize growing seasons between 2013 and 2018

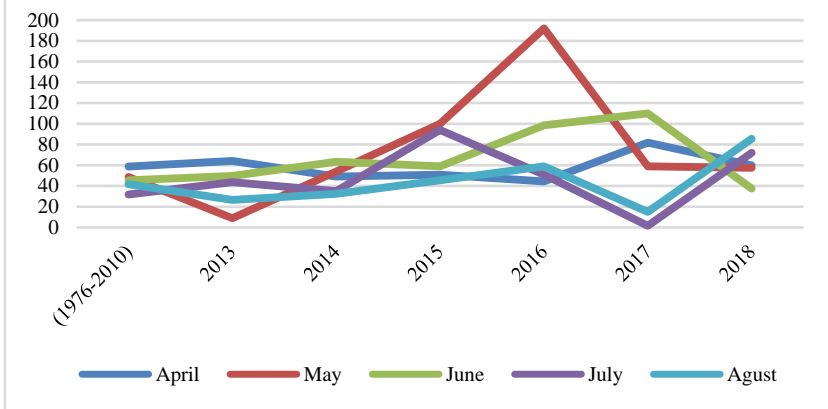

Figure 3. Total precipitation (mm) of the study area during maize growing seasons between 2013 and 2018 (Anonymous, 2019). 


\subsection{Statistical analyses}

The regression coefficient (bi) was computed as described by Finlay and Wilkinson to estimate the stability and adaptability of maize hybrids investigated. The coefficients of regression deviations introduced by Eberhart and Russell (1966) was used as a measure of cultivar stability. The coefficients of linear regression (bi) was used as a measure of the cultivar adaptability. The regression coefficients equal to one coupled with $\mathrm{S}^{2} \mathrm{~d}$ of zero indicate an average adaptation to all environments.

The Additive Main Effect and Multiplicative Interaction (AMMI) analysis was carried out with the adjusted mean values of herbage and dry matter yields to assess the relationship among maize hybrids, locations and GE using the model introduced by Zobel et al. (1988). The method employes the PCA to seperate the multiplicative effects of GE into a number of integrated photocatalytic adsorbent (IPCA). The AMMI analysis uses the following equation;

$$
y_{g e}=\mu+\alpha_{\mathrm{g}}+\beta_{e}+\sum_{n=1}^{N} \lambda_{n} \gamma_{\mathrm{g} n} \delta_{e n}+Q_{\mathrm{g} e}
$$

In this equation; $Y_{g e}$ is the mean dry matter yield or herbage yield of maize hybrids $(G)$ in the environment (E) for replication (r); Additive parameters of $\mu$ is the overall mean; $\alpha_{\mathrm{g}}$ is the deviation of genotype $\mathrm{g}$ from the overall mean, $\beta_{\mathrm{e}}$ is the deviation of the environment; Multiplicative parameters of $\lambda_{\mathrm{n}}$ is the singular value for IPCA, $\gamma_{\mathrm{gn}}$ is the genotype eigenvector for axis $\mathrm{n}$, and $\delta_{\mathrm{en}}$ is the environment eigenvector; cger is error term and $\mathrm{Qge}_{\mathrm{ge}}$ is PCA residual. The $\mathrm{Q}_{\mathrm{ge}}$ is expected to have normal distribution. The AMMI stability value (ASV), introduced by (Purchase et al., 2000), was used to quantify and rank the stability of the genotypes based on their dry matter and herbage yield stabilities.

The ASV is the distance from the origin in a twodimensional scattergram of IPCA plot to the coordinate point (Purchase, 1997). Since the IPCA1 score contributes to the sum of squares (SS) of GEI, a weighted value is needed. The ASV was calculated for each genotype and each environment based on the relative contributions of the IPCA1 and IPCA2 scores to the interaction SS as follows:

$$
A S V=\sqrt{\left[\frac{S S_{I P C A_{1}}}{S S_{I P C A_{2}}}\left(I P C A_{1}\right)\right]^{2}+\left(I P C A_{2}\right)^{2}}
$$

In the equation, SSIPCA1 / SSIPCA2 is the weight given to the IPCA1-value by dividing the IPCA1 sum of squares by the IPCA2 sum of squares (Purchase, 1997). The yield stability index (YSI) statistic (Farshadfar et al., 2011) was used to determine the high-yielding and stable maize hybrids. The YSI for maize hybrids was calculated based on the ranking of mean dry matter and herbage yields of maize hybrids (RY) and rank of ASV (RASV) in a single criterion (YSI). The YSI was calculated as follow;

$$
\text { YSIi }=\text { RASV }+ \text { RY }
$$

The ranks of maize hybrids were assigned for the mean yield and stability parameters, therefore the maize hybrid with the highest yield and the lowest estimated value for each statistic was considered as rank 1 (Farshadfar et al., 2011; Roostaei et al., 2014).

The genotype main effect (G) plus genotype $x$ environment (GE) interaction (G+GE) biplot (GGE) analyses (Yan et al., 2000; Yan and Tinker 2006) was applied for the GE assessment of dry matter and herbage yields of maize hybrids. The GGE biplot model was constructed based on the following equation:

$$
K(Y i j)=\mu+\beta j+K \Sigma \delta k \gamma i k \eta j k k+1
$$

In the equation; $K(Y i j)$ is the expected response of a genotype in an environment (j); $\mu$ is the overall mean; $\beta j$ is the environment effect; $\mathrm{K}$ represents the number of PCs needed to provide an adequate explanation of $\mathrm{G}+\mathrm{GE}$; $\eta \mathrm{jk}$ is the singular value for the kth PC; and the $\delta k$ and are $\gamma \mathrm{jk}$ the ith genotype score and the jth environmental score for the kth PC. Singular value $\eta j k$ partitioning is obtained by providing a scaling factor $\mathrm{f}$ to obtain alternative genotype $(\mathrm{cik}=\delta \mathrm{fk})$ and environment scores. The symmetric scaling $(f=0.5)$ was used in $(\gamma i k)(\mathrm{djk}=\delta 1 \mathrm{k}-\mathrm{f} \eta j k)$ visualizing which-wins-where pattern of MET data, due to its compliance with most of the features related to other benchmarking methods (Yan, 2002). The GenStat v. 12 statistical software was used to compute all the analysis.

\section{Results and discussion}

\subsection{The AMMI analysis}

The AMMI analysis of variance indicated a significant effect $(\mathrm{P}<0.01)$ of $\mathrm{G}, \mathrm{E}$ and GE. The partitioning of SS indicated that effect of environment was the major source of variation in herbage and dry matter yields of maize hybrids followed by genotype and GE in dry matter yield and GE and genotype in herbage yield. The SS for environment main effect represented 54.23 and $60.38 \%$ of the total variation in herbage and dry matter yields, respectively. The environment effect was 2 to 3 times higher than GE effect, which indicates possible inclusion of different MEs in the METs data (Table 2). The environment explains most of the variation in genotype, when variations of G and GE are usually smaller (Yan, 2002). Similar results on greater effect of $E$ compared to the G and GE in grain yield have been reported by other researchers (Gauch and Zober 1997; Deghani et al., 2006; Rakshit et al., 2012; Bantayehu et al., 2013; Rezene, 2014; Munawar et al., 2013; Mohammadi et al., 2015; Doğan et al., 2016; Kendal and Tekdal 2015; Kendal and Sayar 2016; Faria et al., 2017; Oliveira et al., 2017). The AMMI separates the additive variance from the multiplicative variance and evaluates the major component axes or more together. This process reveals information on the impact ratio of each variable in GE interaction. In addition, separating the main and interaction effect enables the AMMI capture the most part of the $\mathrm{G} x \mathrm{E}$ sum of squares (Gauch, 2006). The result of AMMI analysis indicated that $76.44 \%$ of total variation in PC1, $18.94 \%$ in PC2, $4.07 \%$ in PC3 and $0.55 \%$ in PC4 accounted for the GE interaction $(\mathrm{P}<0.01)$. Yan et al. (2009) indicated that if the first two PCs account for almost $60 \%$ of the variance in the data and combined effect explains less than $10 \%$ of the total variability, then the biplot is considered adequately elaborating the variability in the GE data. The PC1 and PC2 explained $94.27 \%$ of the variability in herbage yield. The herbage yield of maize hybrids ranged from $50.29 \mathrm{t} \mathrm{ha}^{-1}$ (DKC7211-2016) to $73.41 \mathrm{t} \mathrm{ha}^{-1}$ (SAMADA07-2017) with an average value of $62.01 \mathrm{t} \mathrm{ha}^{-1}$. The lowest herbage yield was obtained in DKC 7211 hybrid $\left(57.15 \mathrm{t} \mathrm{ha}^{-1}\right)$ while the highest herbage yield was in Burak hybrid (64.98 $\left.\mathrm{t} \mathrm{ha}^{-1}\right)$. 
The mean herbage yield during the experiment was between $57.89 \mathrm{t} \mathrm{ha}^{-}$in 2016 and $71.14 \mathrm{t} \mathrm{ha}^{-1}$ in 2017. (Table 3) Similar results have been reported in other studies (Ozata et al. 2012; Ozata et al. 2018). The x-axis in an AMMI model represents the $G$ and $E$ main effect and $y$-axis represents the GE interaction effects (Figure 4). The results of AMMI analysis revealed that the stability of PR31Y43 and Burak hybrids were higher than other hybrids because they were closer to the zero points of the $\mathrm{x}$ and $\mathrm{y}$ axes. In contrast, Samada 07, DKC7221 and DKC7211 were less stable maize hybrids as indicated by the distances from the $\mathrm{x}$ axis (Table 3).

\subsection{The GGE biplot analysis for herbage yield}

The first two PCs of GE interaction accounted for $94.27 \%$ of the total effect in herbage yield variation. The first principal component (IPCA1) explained the $72.57 \%$ of the total variation caused by the GE interaction, while IPCA2 accounted for $21.69 \%$ of the variation (Figure 5, Table 1). The model adequately explained the variability in the GE interaction (Yan and Rajcan, 2002). The GGE biplot provided good explanation of the pattern, regarding the first two IPCs. The relationships among genotypes and environments were shown in Figure 5.

The GGE biplot can explain GE interaction well against environmental variations for genotypes with different sensitivities. In addition, the suitability of a genotype for a particular environment can also be determined by GGE biplot a (Li et al., 2006; Kendal et al., 2016). The yield stability of PR31Y43 and Burak genotypes were close to each whereas DKC7211, SAMADA07 and DKC7221 were different for the herbage yield stability (Figure 5 and Table $3)$.

Table 1. Descriptive characteristics of commercial hybrids investigated

\begin{tabular}{ccccc}
\hline Genotype & Origin & Cycles (Maturity)/Colors & Type & Grain texture \\
\hline SAMADA 07 & KTAE/TURKEY & Late/ Yellow & Single Hybrid & Semi-dent/Semi-hard \\
PR31Y43 & DU PONT/USA & Late/ Yellow & Single Hybrid & Dent \\
BURAK & BATEM/ TURKEY & Late/ Yellow & Single Hybrid & Semi-dent/Semi-hard \\
DKC7211 & DEKALP/ USA & Late/ Yellow & Single Hybrid & Dent \\
DKC7221 & DEKALP/ USA & Late/ Yellow & Single Hybrid & Dent \\
\hline
\end{tabular}

Table 2. Main effects and interactions for fresh herbage and dry matter yields of maize hybrids

\begin{tabular}{|c|c|c|c|c|c|c|c|c|c|c|}
\hline \multirow[b]{2}{*}{ Source } & \multicolumn{6}{|c|}{ Herbage yield } & \multicolumn{4}{|c|}{ Dry matter yield } \\
\hline & $\mathrm{df}$ & SS & MS & F prob & $\%$ & $\mathrm{df}$ & SS & MS & F prob & $\%$ \\
\hline Total & 89 & 3161.7 & 35.52 & & & 89 & 359.48 & 4.03 & & \\
\hline Treatments & 29 & 3068.6 & 105.81 & $13560.3^{* *}$ & & 29 & 347.44 & 11.98 & $15667.91 * *$ & \\
\hline Genotypes & 4 & 673.2 & 168.3 & $21568.59 * *$ & 21.94 & 4 & 61.74 & 15.43 & $20185.72 * *$ & 17.77 \\
\hline Environments & 5 & 1664 & 332.8 & $43.06 * *$ & 54.23 & 5 & 209.8 & 41.96 & $41.98 * *$ & 60.38 \\
\hline Block & 12 & 92.7 & 7.73 & $990.39 * *$ & 3.02 & 12 & 12 & 1 & $1307.23 * *$ & 3.45 \\
\hline GE & 20 & 731.4 & 36.57 & $4686.28 * *$ & 23.83 & 20 & 75.9 & 3.79 & $4962.86^{* *}$ & 21.85 \\
\hline IPCA1 & 8 & 559.1 & 72.57 & $8956.46 * *$ & 76.44 & 8 & 55.20 & 6.25 & $8182.54 * *$ & 72.53 \\
\hline IPCA2 & 6 & 138.5 & 21.69 & $2957.99 * *$ & 18.94 & 6 & 15.89 & 3.04 & $3976.55 * *$ & 20.94 \\
\hline IPCA3 & 4 & 29.8 & 7.44 & 953.29ns & 4.07 & 4 & 3.66 & 1.41 & 1850.88ns & 4.88 \\
\hline IPCA4 & 2 & 4.0 & 2.0 & 256.41ns & 0.55 & 2 & 1.15 & 0.96 & 1267ns & 1.51 \\
\hline Residuals & & & & & & & & & & \\
\hline Error & 48 & 0.4 & 0.01 & & & 48 & & 0.001 & & \\
\hline
\end{tabular}

SS; Sum of Square, MS: mean of square*, ** Significant at 1\%, $\% 5$ level of probability

Table 3. The herbage yield $\left(\mathrm{tha}^{-1}\right)$ by AMMI- per environment during the years studied

\begin{tabular}{|c|c|c|c|c|c|c|c|c|c|c|c|c|c|c|}
\hline & $\begin{array}{c}E \\
2013 \\
\end{array}$ & $\mathrm{R}$ & $\begin{array}{c}E \\
2014\end{array}$ & $\mathrm{R}$ & Е 2015 & $\mathrm{R}$ & $\begin{array}{c}E \\
2016\end{array}$ & $\mathrm{R}$ & $\begin{array}{c}E \\
2017\end{array}$ & $\mathrm{R}$ & $\begin{array}{c}E \\
2018\end{array}$ & $\mathrm{R}$ & Mean & Rank(A) \\
\hline SAMADA 07 & 57.29 & 4 & 65.21 & 1 & 57.01 & 5 & 63.88 & 1 & 73.42 & 1 & 68.26 & 2 & 64.2 & 2 \\
\hline PR31Y43 & 63.11 & 3 & 61.39 & 3 & 58.84 & 3 & 59.05 & 3 & 68.99 & 5 & 61.91 & 3 & 62.2 & 3 \\
\hline Burak & 62.77 & 1 & 64.66 & 2 & 60.74 & 2 & 62.21 & 2 & 71.19 & 3 & 68.36 & 1 & 65.0 & 1 \\
\hline DKC7211 & 53.38 & 5 & 54.95 & 5 & 57.69 & 5 & 50.29 & 5 & 69.79 & 4 & 56.85 & 4 & 57.2 & 5 \\
\hline DKC7221 & 62.71 & 2 & 60.92 & 4 & 63.96 & 1 & 54.04 & 4 & 72.33 & 2 & 55.17 & 5 & 61.5 & 4 \\
\hline Mean & \multicolumn{2}{|c|}{59.85} & \multicolumn{2}{|c|}{61.43} & \multicolumn{2}{|c|}{59.65} & \multicolumn{2}{|c|}{57.89} & \multicolumn{2}{|c|}{71.14} & \multicolumn{2}{|c|}{62.11} & & \\
\hline IPCAe1 & \multicolumn{2}{|c|}{-1.30034} & \multicolumn{2}{|c|}{0.39938} & \multicolumn{2}{|c|}{-2.03743} & \multicolumn{2}{|c|}{1.55304} & \multicolumn{2}{|c|}{-0.76997} & \multicolumn{2}{|c|}{2.15532} & & \\
\hline IPCAe2 & \multicolumn{2}{|c|}{1.80389} & \multicolumn{2}{|c|}{$\begin{array}{r}0.18530 \\
-087519\end{array}$} & \multicolumn{2}{|c|}{-0.42623} & \multicolumn{2}{|c|}{0.48128} & \multicolumn{2}{|c|}{-1.73036} & \multicolumn{2}{|c|}{-0.31388} & & \\
\hline IPCAe3 & \multicolumn{2}{|c|}{0.24425} & \multirow{2}{*}{\multicolumn{2}{|c|}{-0.87519}} & \multicolumn{2}{|c|}{0.53183} & \multicolumn{2}{|c|}{-0.70384} & \multicolumn{2}{|c|}{-0.38055} & \multicolumn{2}{|c|}{1.18349} & & \\
\hline IPCAe4 & \multicolumn{2}{|c|}{0.38684} & & -0.68177 & \multicolumn{2}{|c|}{-0.43701} & \multicolumn{2}{|c|}{0.26831} & \multicolumn{2}{|c|}{0.52338} & \multicolumn{2}{|c|}{-0.05976} & & \\
\hline
\end{tabular}

The effect of environmental factors is directly proportional to the length of the vector, which is used in estimating the discriminating power of an environment. The longest vector (distance from biplot origin to the yield of a genotype) indicates the best performance or ideal genotype, the shortest vector does not provide sufficient information on the performance of a genotype (Yan et al., 2007). The longest vector to the origin in 2016 and 2018 was environmental vector that points out the ideal environment in differentiating the genotypes. The vector length in 2017 was the lowest, indicating insufficient responsive of genotypes to the interaction with the environments. However, environmental vectors were of great importance in terms of others and their similarities, and the differences can be discriminated with this method. Two environments are considered positively correlated if the angle between their environmental vectors, 
represents the correlation coefficient between them, is less than $90^{\circ}$ while negatively correlated if the angle is higher than $90^{\circ}$, and independent if the angle is equal to $90^{\circ}$ (Yan and Tinker 2006). Positive correlations in herbage yields were recorded between the years of 2014, 2016, 2017 and 2018 due to the angle of the vectors $\left(<90^{\circ}\right)$. In contrast, negative correlations were recorded between 2015 and 2018 indicated by the environmental vector angle $\left(>90^{\circ}\right)$ (Figure 5).

The Scatter plot (which-won-where) polygon correlates genotypes with each other and the environment with respect to herbage yield from multiple environmental conditions and shows which genotype is more compatible with which environment. There are positive interactions if genotypes and environments are placed in the same sector, and negative relations if the genotypes are located in different sectors (Yan, 2002). The PR31Y43 and Burak genotypes and 2014, 2016, 2017 and 2018 years had positive correlations. Similarly, DKC7221 maize genotype had a positive relationship with 2015, while a negative relationship was detected between DKC7211 and all experimental years (Figure 6). The years were basically divided into four sectors comparing the herbage yields of maize hybrids with each other. Samada 07 genotype was placed in the first sector together with 2016 and 2018 years, and Burak variety was located in the second sector together with 2014 and 2017. The PR31Y43 and DKC7221 hybrids were in the third sector with 2013 and 2015, and DKC7211 was in the fourth sector. The study conducted in the same environment for six years showed that the years were different from each other in terms of herbage yield of maize genotypes (Figure 6). The effect of this method on the environment is different from each other (Yan and Tinker 2006; Putto et al., 2008; Ahmadi et al., 2012; Muntaz et al., 2019).

The reliability of the environment is important in determining the test environments chosen for the genotypes. The ideal test environment should be distinctive and also provide information about the performance of genotypes. The year 2013 and 2015 were determined as the first mega environment, and 2014, 2016, 2017 and 2018 are identified as the second mega environment. The first mega environment is the ideal test environment for the DKC7221 genotype and the second mega environment is ideal for the herbage yield of PR31Y43, Burak and SAMADA07 maize hybrids (Figure 7). A similar approach for the mega environment identification and specific adaptation were used by Yan et al. (2000), Yan and Rajcan (2002), Yan and Tinker (2006), Putto et al. (2008); Ahmadi et al. (2012) and Muntaz et al. (2019).

Ranking the genoypes in biplot method provided an information on the overall superiority or usefulness of genotypes to determine the most suitable variety in all environments (Yan and Frégeau-Reid 2018). The PR31Y43 genotype among the five maize hybrids investigated was the closest genotypes to the stability line; thus, is considered the ideal genotype for all environments. The results indicated that PR31Y43, Samada07 and Burak maize hybrids were close to the average yield line and DKC7211 and DKC7221 hybrids were below the ideal yield line. The Biplot Ranking model facilitates the visual comparison; therefore, plant breeders frequently used the biplot ranking to assess the stability and adaptability of genotypes (Gauch and Zobel 1997; Yan et al., 2000; Yan et al., 2001; Yan and Rajcan 2002; Yan 2002; Yan and Kang 2003; Yan and Tinker 2006: Yan et al., 2007 Ahmadi et al., 2012; Mortazavian et al., 2014; Kendal et al., 2016).

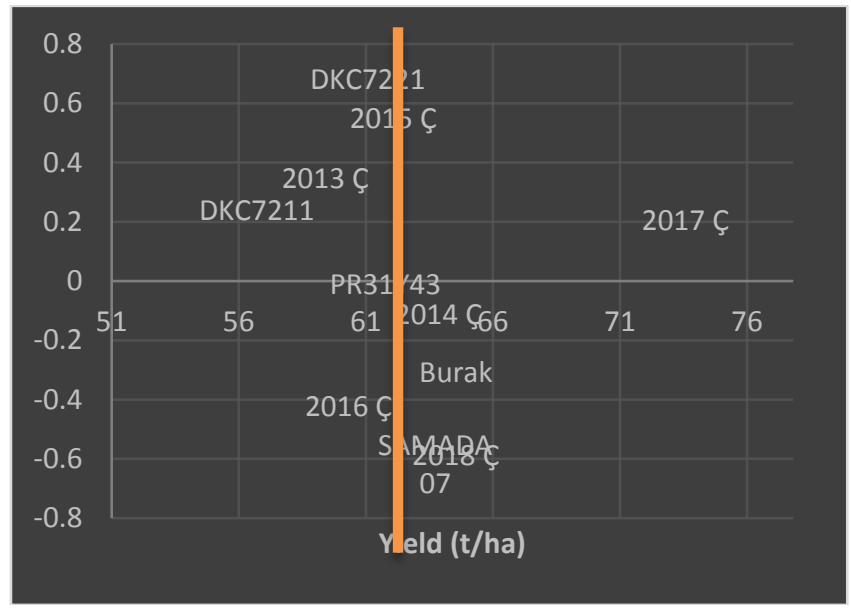

Figure 4. The AMMI1 biplot of IPCA1 scores versus mean herbage yield of silage maize hybrids

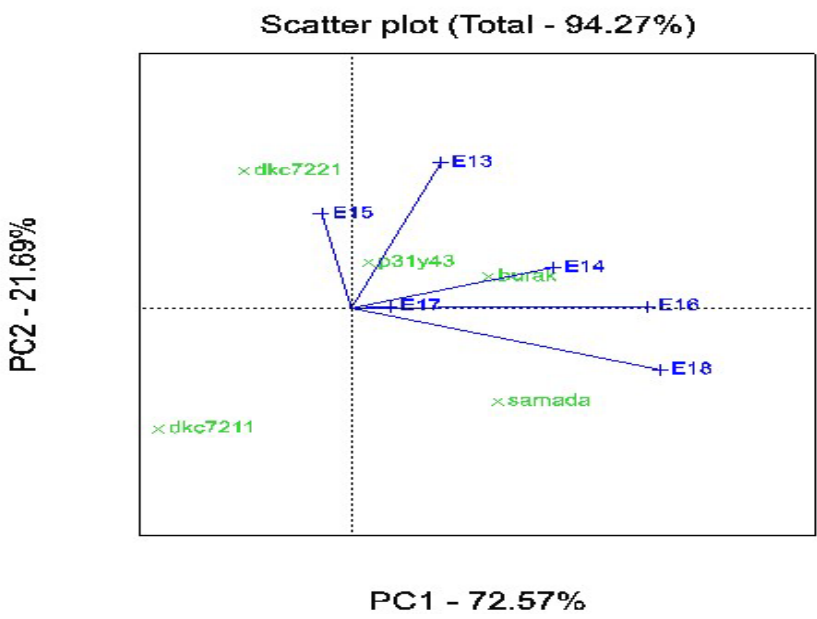

Figure 5. The GGE biplot for the relationships among the years

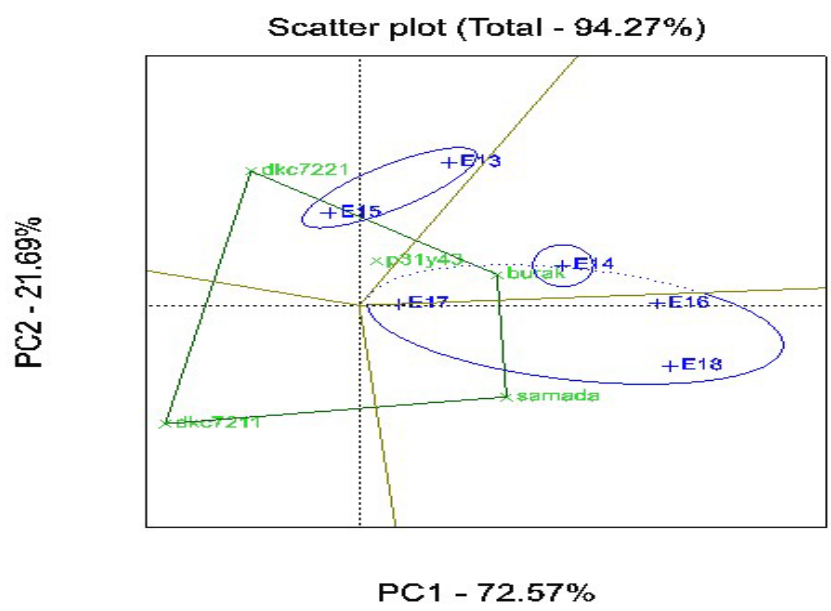

Figure 6. The polygon (which-won-where) scatter plot of five maize hybrids tested during six years. 
The genotype comparison in biplot model showed the ideal region (indicated by the arrow) as a representative of the mean herbage yield values in all locations and provided information on the maize hybrids in the ideal region. The comparison in biplot graph revealed that PR31Y43 and Burak hybrids located in the ideal environment shown by the arrow and limited by the circle, were the maize hybrids that should be used primarily for the region. The closest genotype to the circle was SAMADA07; therefore, SAMADA07 genotype should be preferred in the second degree, and the DKC7211 and DKC7221 genotypes should be preferred as the third degree (Figure 7). Comparison biplot model has been used in the selection and adaptation studies to determine the ideal genotype based on average data. Similar results have been reported by several researchers using the GGE Biplot model (Dehghani et al., 2006; Jalata 2011; Kendal and Sayar 2016).

The mean yield performance and stability of genotypes were evaluated by an average environment coordination (AEC) method (Yan, 2001; Yan et al, 2000; Yan, 2002; Yan et al. 2009; Yan et al. 2010). In the average environmental coordinate system, AEC $\mathrm{x}$ axis (PC1) passes through the biplot origin with an arrow indicating the positive end of the axis and indicates the mean performance axis of the genotypes. The stability of the five maize hybrids was assessed using the biplot for herbage yield (Figure 8). The ASV values revealed the variations in herbage yield stability among the 5 genotypes (Table 6). In the AEC method, a variety with ASV value close to zero is defined as the stable genotype. Consequently, PR31Y43 (ASV=0.06) and Burak (2.62) genotypes were determined as the most stable, while DKC7211 (4.08), SAMADA07 (9.21) and DKC 7221 (10.22) genotypes were the least stable genotypes (Table 4, Figure 9).

\subsection{Stability index for herbage yield}

The performance of the varieties increases with the improvement of the environmental conditions. The deviations from regression over environmental averages has been used as a measure of the genotype stability (Eberhart and Russell 1966). A genotype with a high mean yield value, a regression coefficient of unity (bi= 1 ), and the lowest deviation from the regression coefficient $\left(\mathrm{S}^{2} \mathrm{di}\right)=0$ or close to the values of non-significant deviation is defined as a stable genotype (Eberhart and Russell 1966). The regression coefficient (bi) of maize hybrids ranged from 0.61 to 0.92 , the deviation from mean square regression ranged from 9.144 to 89.044, and the regression line intercept (a) constant was between -1.344 and 27.688 (Table 5, Figure 10-11). The stability values of genotypes indicated that Burak genotype had a high stability along with PR31Y43. In contrast, the stability of SAMADA07, DKC7211 and DKC7211 genotypes were low.

\subsection{The AMMI analysis of dry matter yield}

The AMMI analysis indicated a significant $(\mathrm{P}<0.01)$ variation among $G, E$ and GE in dry matter yield of maize hybrids. The partitioning of SS values indicated that environment effect was the predominant source of variation followed by GE interaction and genotype effect. The differences between genotypes explained $21.94 \%$ of dry matter yield in total variation, while the effects of GE interaction explained $23.83 \%$ of the total variation. The sum of squares for environment main effect represented $60.38 \%$ of the total variation in dry matter yield. The differences in genotypes explained $17.77 \%$ of total variation in dry matter yield, while the effects of GE interaction explained 21.85\% of the total variation (Table 2). The genotypes are considered suitable for all environments, when the mean component axis values of the genotypes in the AMMI model are close to zero. In addition, the model is considered accurate to evaluate the major component axes or more together. The model provides information for the effects of each axis on GE interaction. The results of AMMI analysis revealed that $65.96 \%$ of the GGE total variation in dry matter yield accounted for PC1, $24.03 \%$ for PC2, $7.46 \%$ for PC3 and $2.56 \%$ for PC4 (Table 2). The PC1 and PC2 explained $68.30 \%$ of the total variation, which indicated that the biplot adequately elaborates the variability in the GE dry matter yield data.

Dry matter yield of maize genotypes was between 18.17 $\mathrm{t} \mathrm{ha}^{-1}$ (DKC7211) and $26.23 \mathrm{t} \mathrm{ha}^{-1}$ (SAMADA07-2017) with a mean value of $22.30 \mathrm{t} \mathrm{ha}^{-1}$. The DKC7111 genotype had the lowest (20.75 t ha-1), while the Burak hybrid had the highest mean dry matter yield $\left(23.17 \mathrm{t} \mathrm{ha}^{-1}\right)$. The mean dry matter yield during the experiment varied from $20.71 \mathrm{t} \mathrm{ha}^{-1}$ in 2016 to $25.37 \mathrm{t} \mathrm{ha}^{-1}$ in 2017 (Table 6). The results of AMMI analysis indicated that PR31Y43 and SAMADA07 hybrids were more stable for dry matter yield because they were closer to the origin of the $\mathrm{x}$ and $\mathrm{y}$ axes, while Burak, DKC7211 and DKC7221 genotypes were less stable than the other maize hybrids (Figure 12). Similar results have been reported by several other researchers (Bantayehu et al., 2013; Rezene, 2014; Kendal and Tekdal, 2015; Kendal and Tekdal, 2016; Kendal and Sayar, 2016; Faria et al., 2017; Oliveira et al., 2017).

\subsection{The GGE biplot analysis of dry matter yield}

The application of AMMI model for partitioning of GE interaction using an approximate F-statistic (Gollob, 1968) also revealed that the first two IPCAs were significant $(\mathrm{P}<0.001)$ in explaining the effect on dry matter yield of maize varieties (Table 7). The two IPCAs of GE interaction accounted for $93.48 \%$ of the total effect on dry matter yield variation. The IPCA 1 accounted for $72.53 \%$ of the variation caused by the interaction, while IPCA2 accounted for 20.94 $\%$ of the variation (Table 2 ).

The GGE biplot models explain the GE interaction of genotypes with different sensitivity in environmental variations. In addition, a GGE biplot model clearly shows which genotype is more suitable for which environment and reveals the compatibility rates of genotypes for the environments (Li et al., 2006; Kendal et al., 2016b). The scatter plot of mean dry matter yield of maize hybrids revealed that the stability of PR31Y43 and Burak hybrids was close to each other, while the stabilities of DKC7211, SAMADA07 and DKC7222 hybrids were different from each other (Figure 14).

The discrimination $\times$ representativeness graphs allowed to determine the type of environment to distinguish the genotypes. The longest of the vector to the origin in 2016 and 2018 were environmental vectors, indicated the ideal environment to differentiate the maize genotypes for dry yield matter.The lowest vector length was obtained in 2017 
that does not provide adequate information on the differences in genotypes in terms of dry matter yield. Positive relationships were obtained in the dry matter yields of maize hybrids among 2014, 2016, 2017 and 2018 years indicated by the vector angles less than $90^{\circ}$. In contrast, negative and insignificant relationships were recorded in dry matter yields between 2015 and 2018 years as indicated by the vector angles higher than $90^{\circ}$ (Figure 14).

Positive relationship was obtained in dry matter yield of PR31Y43 maize hybrid recorded in 2014, 2016 and 2018. Similarly, a positive relationship in dry matter yields of DKC7221 and PR31Y43 hybrids was determined in 2013 and 2015. Positive relationship in dry matter yield obtained for SAMADA07 hybrid in 2017 was also recorded in the

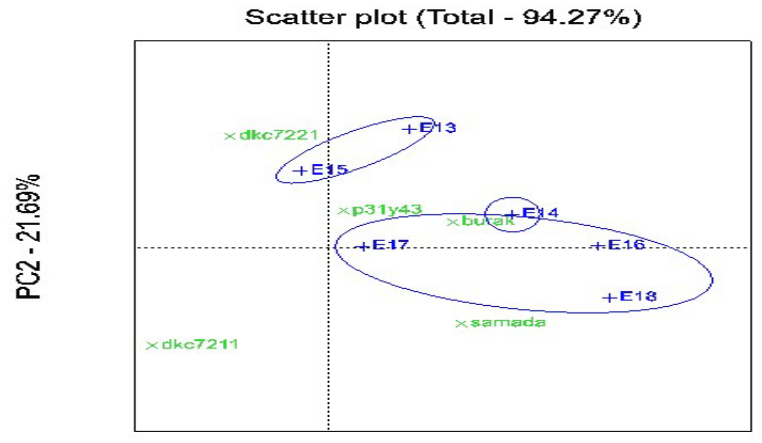

PC1 $-72.57 \%$

Figure 7. The potential and ideal mega environments for the five maize hybrids

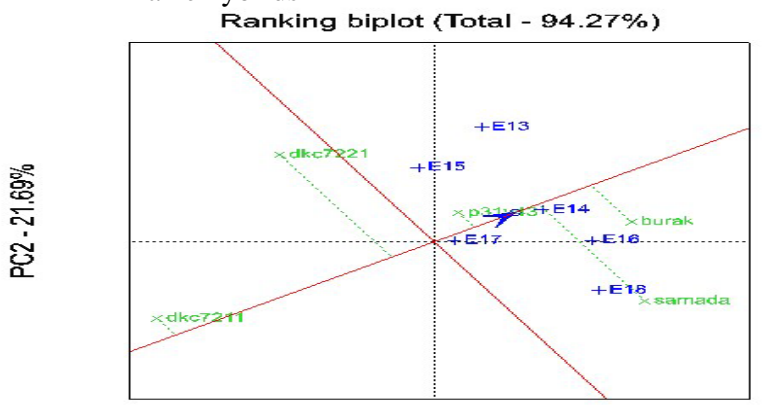

$\mathrm{PC} 1-72.57 \%$

Figure 8. GGE biplot representing the means $\times$ stabilities indicating the herbage yields and production stabilities of five maize hybrids

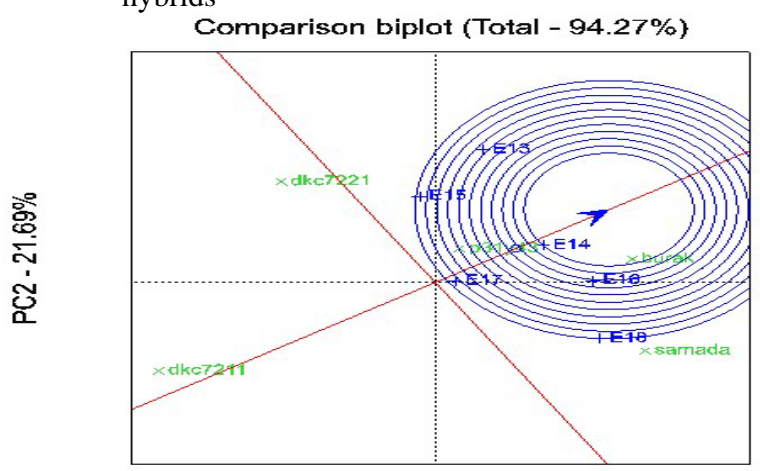

PC1 - 72.57\%

Figure 9. Comparision of herbage yield of five maize hybrids in GGE piplot to the estimate the ideal genotype study. In contrast, a negative relationship was found in dry matter yield of DKC7211 hybrid in all experimental years (Figure 14).

The environments were basically divided into four sectors in comparison of the maize varieties with each other in terms of dry matter yield. SAMADA07 variety and 2017 year was located in the first sector. Burak variety and 2014, 2016 and 2018 were placed in the second sector. The PR31Y43 and DKC7221 maize hybrids and 2013 and 2015 years were in the third sector. The DKC7211 was located in the fourth sector. The results of the study conducted in the same environment for six years revealed that dry matter yields of maize varieties in different years were different from each other (Figure 15).

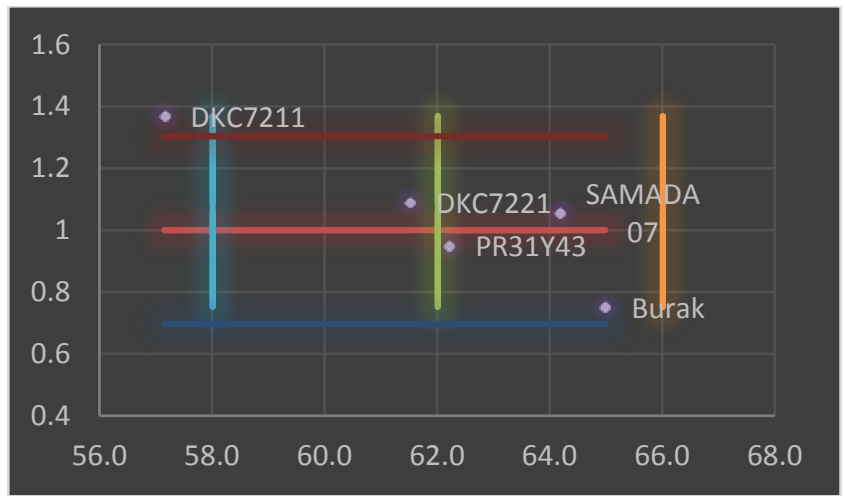

Figure 10. Mean herbage yield ( $\left(\mathrm{ha}^{-1}\right)$ and stability of five maize genotypes

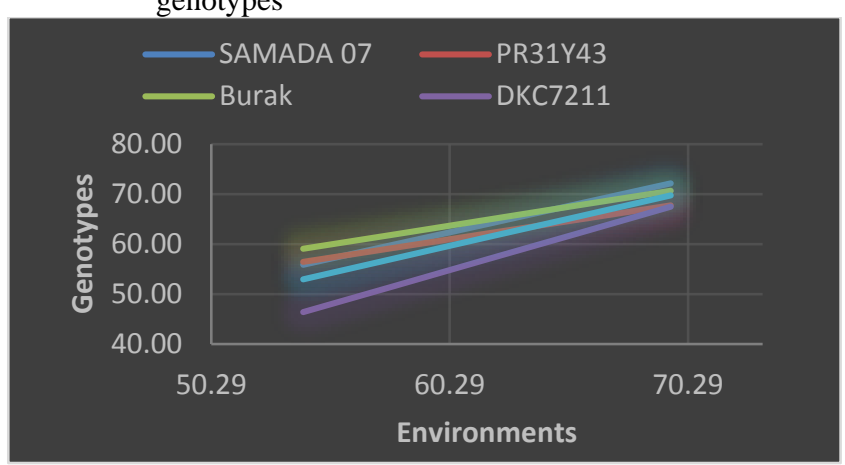

Figure 11. Linear regressions for herbage yield of maize genotypes as a function of the environmental indexes in six environments

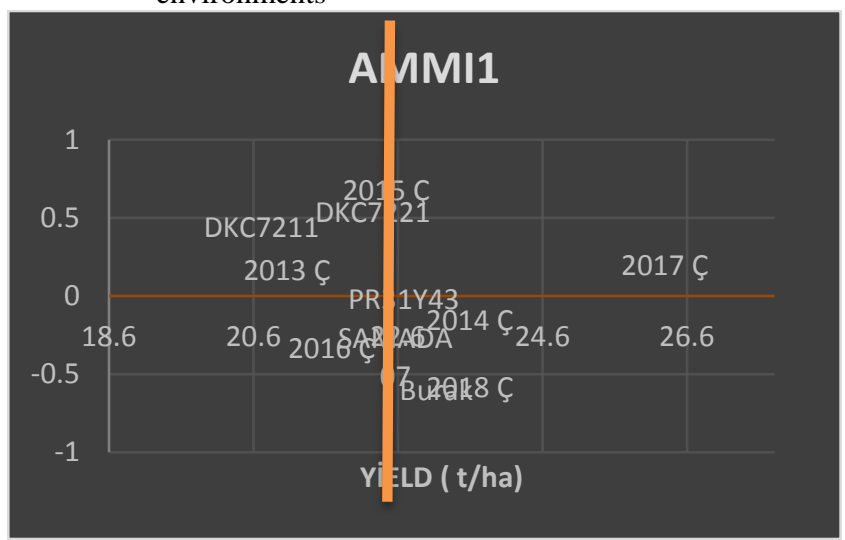

Figure 12. AMMI1 biplot of IPCA1 scores and mean dry matter yields of silage maize genotypes 


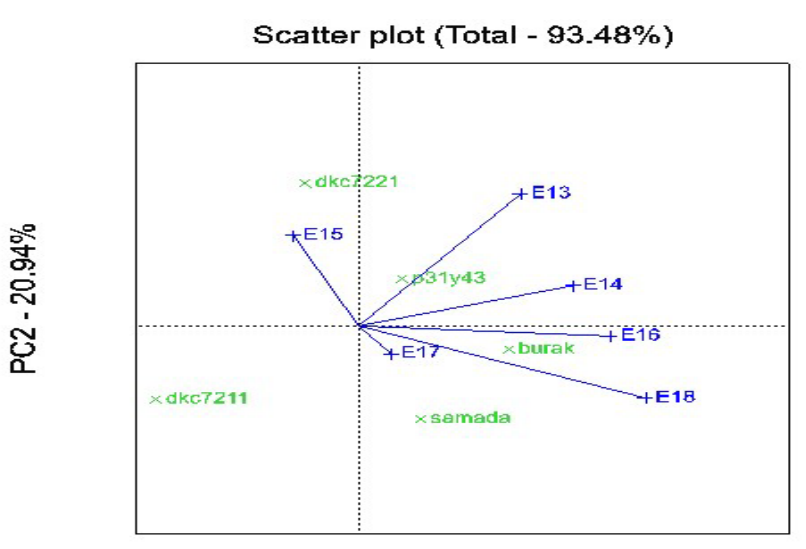

PC1 - 72.53\%

Figure 13. The GGE biplot of dry matter yields of maize hybrids during the experiment

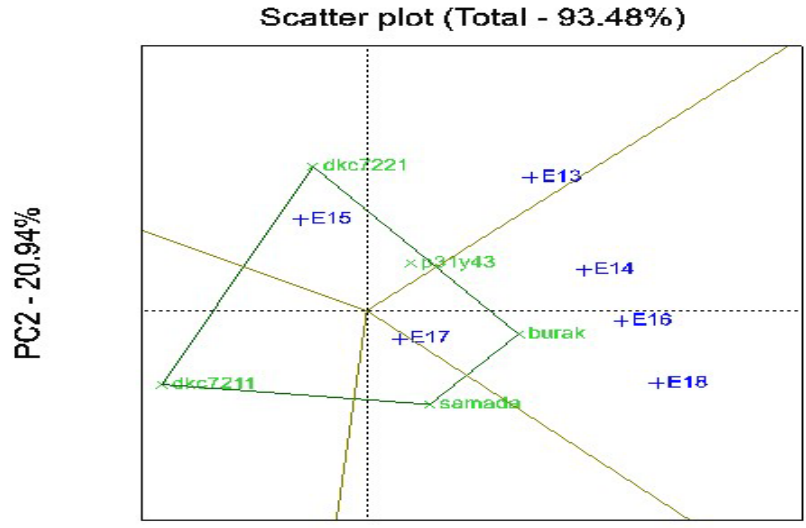

PC1 - 72.53\%

Figure 14. The scatter plot (which-won-where) for dry matter yields of maize genotypes and environments

Table 4. The first four AMMI selections for each of the environments, variances, IPCA scores and YSI parameters

\begin{tabular}{lcccccccccc}
\hline \multirow{2}{*}{ Genotype } & Mean & RANK & IPCA1 & IPCA2 & IPCA3 & IPCA4 & ASV & $\begin{array}{c}\text { ASV } \\
\text { rank (B) }\end{array}$ & $\begin{array}{c}\text { YSI (A } \\
+ \text { B) }\end{array}$ & $\begin{array}{c}\text { YSI } \\
\text { rank }\end{array}$ \\
\hline SAMADA 07 & 64.2 & 2 & 2.2728 & -0.8527 & -0.9952 & 0.0111 & 9.21 & 4 & 6 & 2 \\
PR31Y43 & 62.2 & 3 & 0.0304 & 1.5538 & 0.0536 & 0.7158 & 1.56 & 1 & 4 & 1 \\
Burak & 65.0 & 1 & 1.1274 & 0.7994 & 0.8897 & -0.6461 & 2.62 & 3 & 4 & 1 \\
DKC7211 & 57.2 & 5 & -0.9000 & -1.7219 & 0.8515 & 0.2925 & 4.02 & 2 & 7 & 3 \\
DKC7221 & 61.5 & 4 & -2.5306 & 0.2214 & -0.7996 & -0.3733 & 10.22 & 5 & 9 & 4 \\
\hline
\end{tabular}

Table 5. The stability values of five maize genotypes in different environments for herbage yield ( $\left.\mathrm{t} \mathrm{ha}^{-1}\right)$

\begin{tabular}{lccccc}
\hline \multicolumn{1}{c}{ Genotype } & Mean & $\begin{array}{c}\text { Determination of } \\
\text { coefficient }\end{array}$ & $\begin{array}{c}\text { Regression } \\
\text { coefficient }\end{array}$ & $\begin{array}{c}\text { Deviation from the } \\
\text { mean square } \\
\text { regression }\end{array}$ & $\begin{array}{c}\text { Regression } \\
\text { line } \\
\text { intercept }\end{array}$ \\
\hline SAMADA 07 & $-\mathrm{X}$ & $\mathrm{R}$ & $\mathrm{bi}$ & $\mathrm{S}$ di & $\mathrm{a}$ \\
PR31Y43 & 64.2 & 0.61 & 1.06 & 78.224 & -1.344 \\
Burak & 62.2 & 0.90 & 0.95 & 9.144 & 16.723 \\
DKC7211 & 65.0 & 0.78 & 0.75 & 17.852 & 18.349 \\
DKC7221 & 57.2 & 0.92 & 1.37 & 18.545 & -27.688 \\
Confidence interval & 61.5 & 0.60 & 1.09 & 89.044 & -6.039 \\
\hline
\end{tabular}

The reliability of the environment is of great importance in determining the test environments chosen for genotypes. The ideal test environment should be distinctive and provide information about the performance of genotypes. Three mega environments were identified for the dry matter yields of the maize varieties in the study. The first mega environment consisted of 2013 and 2015, the second mega environment contained 2014, 2016 and 2018 and the third mega environment had only 2017. The first mega environment was ideal to test the dry matter yield of DKC7221 hybrid, the second mega environment was ideal for PR31Y43 and Burak maize hybrids, and the third mega environment was ideal test region for SAMADA07 maize hybrid (Yan and Tinker 2006; Putto et al., 2008; Akcura et al., 2011; Ahmadi et al., 2012; Muntaz et al., 2019).

Ranking biplot method was used to determine the most suitable variety in all environments. The method also untilized to assess the stability of maize hybrid dry matter yield averages in all locations. The genotype closest to the stability line was considered the ideal genotype for all environments. The PR31Y43, SAMADA07 and Burak varieties were close to the mean dry matter yield line, and the DKC7211 and DKC7221 genotypes were below the ideal dry matter yield line. In addition, PR31Y43 and Burak hybrids were the closest genotypes to the ideal stability line indicated by the arrow, and the DKC7221 genotype was the farthest genotype (Figure 15). The biplot ranking model in plant breeding studies has been used an informative feature to facilitate visual comparison and to assess the stability and adaptability of genotypes (Gauch and Zobel 1997; Yan et al., 2000; Yan et al., 2001; Yan and Rajcan 2002; Yan 2002; Yan and Kang 2003; Yan and Tinker 2006: Yan et al., 2007; Ahmadi et al., 2012; Mortazavian et al., 2014; Kendal et al., 2016; Oral et al., 2018).

The ideal region (indicated by the arrow) as a representative of the dry matter yield values in all locations were determined by comparision of the biplot model. The comparision also provided information on the maize hybrids in the ideal region. The PR31Y43 and Burak genotypes were located in the ideal environment indicated by the arrow and 
limited by the circle. The PR31Y43 and Burak hybrids should be preferred to grow in this region. The SAMADA07 and DKC7221 varieties are the next hybrids which should be preferred due to the relatively higher distance to the circle. The DKC7211 hybrids should be the last preference to be grown in the region (Figure 16). Comparison biplot model have been used to determine the optimal genetypes for adaptation studies. Similar results using the GGE Biplot model have been reported by several other researchers (Dehghani et al., 2006; Kaya et al., 2006; Akcura et al., 2011; Jalata, 2011; Rakhsit et al., 2012; Karimizade et al., 2013; Kendal and Sayar, 2016; Oral et al., 2018; Muntaz 2019).The stability of the genotypes in dry matter yield was assessed using the biplot (Figure 17). The ASV indicated variations in dry matter yield stability among five maize hybrids (Table 6). The DKC7221 (0.30) and PR31Y43 (0.58) genotypes were the most stable, while Burak (1.01), DKC7211 (1.04) and SAMADA07 (0.85) genotypes were the least stable genotypes (Table 7).

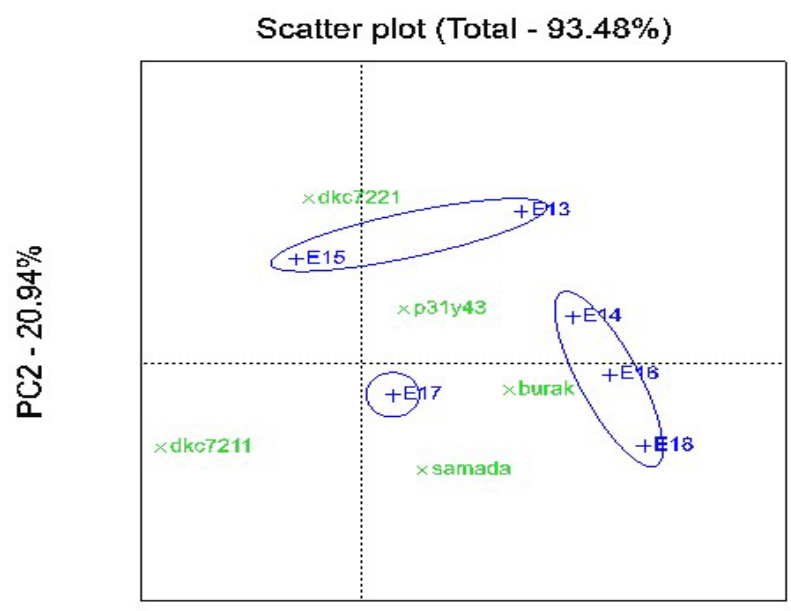

$P C 1-72.53 \%$

Figure 15. The potential and ideal mega-environments to test the dry matter yields of maize hybrids

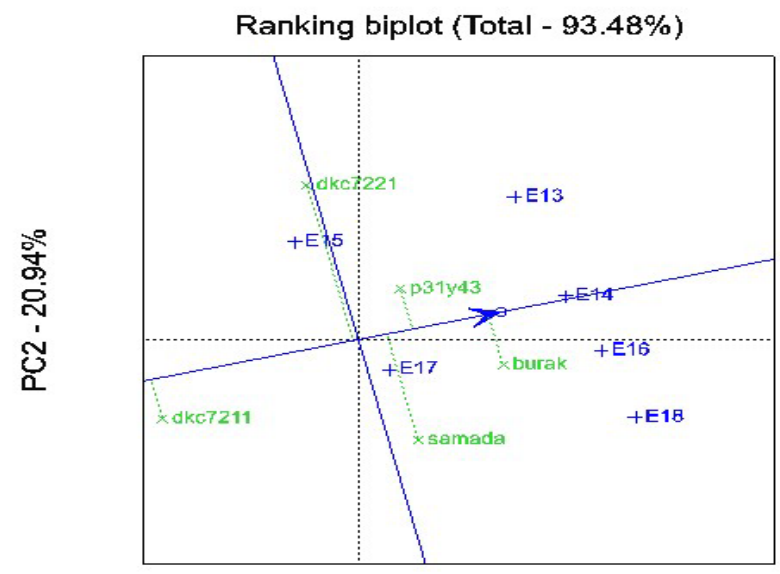

PC1 - 72.53\%

Figure 16. GGE biplot representing the means $\times$ stabilities indicating the dry matter yields and respective production stabilities of five maize hybrids

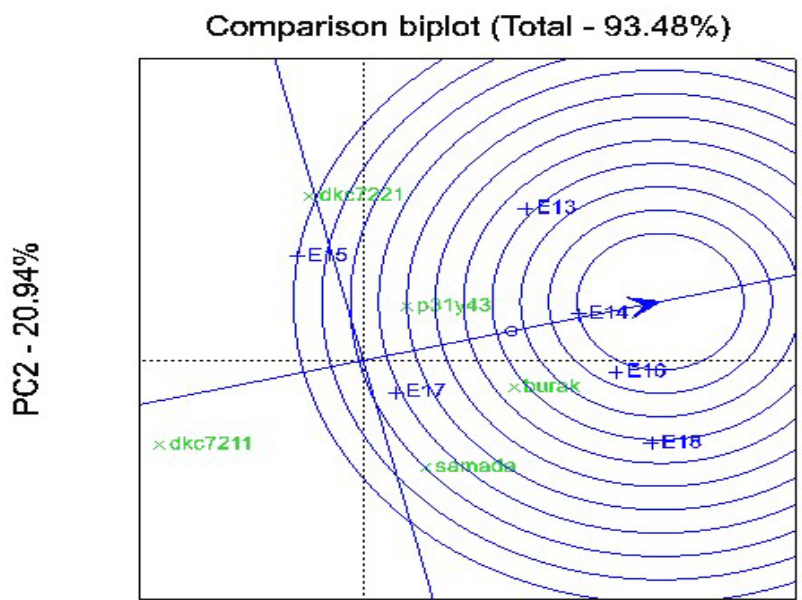

PC1 - $72.53 \%$

Figure 17. Comparision of dry matter yield of five maize hybrids in GGE biplot to estimate the ideal genotype

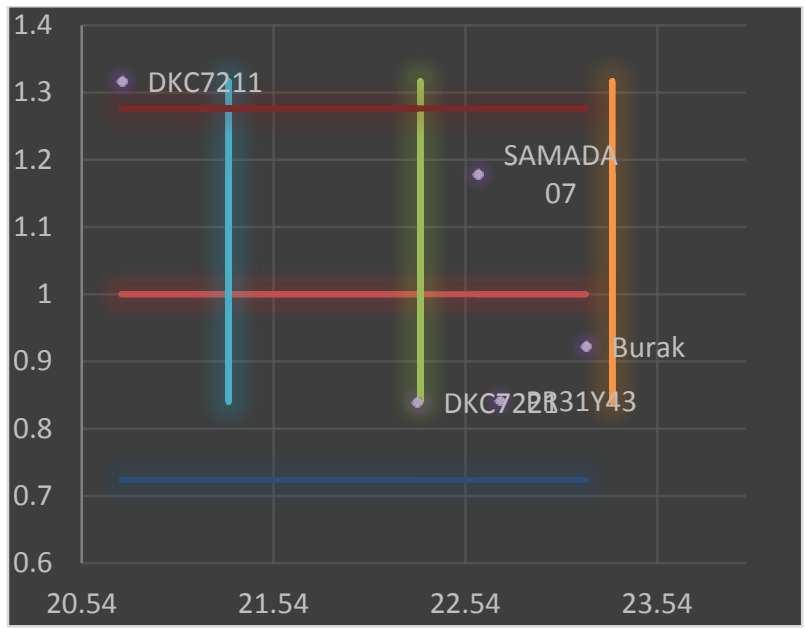

Figure 18. Mean dry matter yield $\left(\mathrm{t} \mathrm{ha}^{-1}\right)$ and stability values of five maize genotypes

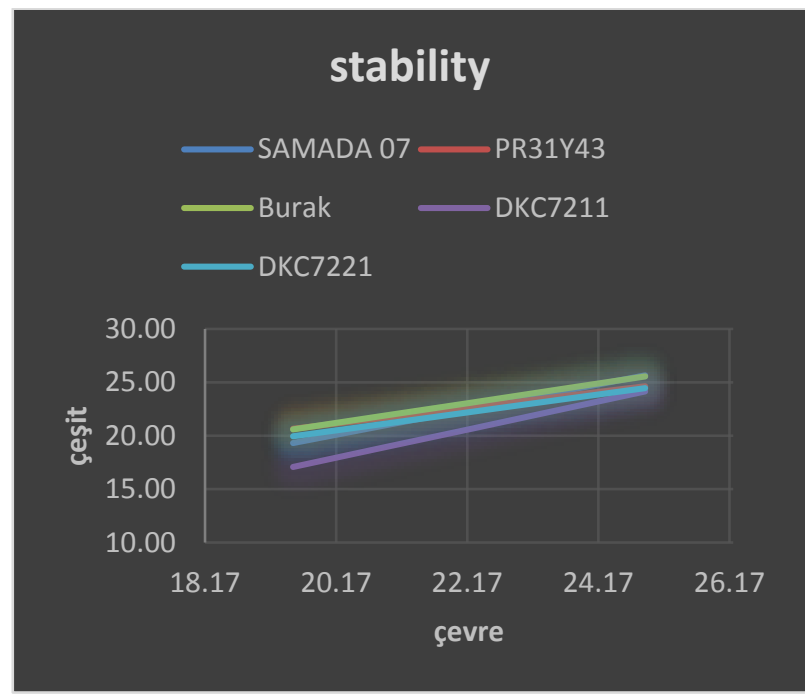

Figure 19. Linear regressions for dry matter yield of genotypes as a function of the environmental indexes for six years 
Table 6. The AMMI estimates of dry matter yield $\left(\mathrm{t} \mathrm{ha}^{-1}\right)$ for different years of the experiment

\begin{tabular}{|c|c|c|c|c|c|c|c|c|c|c|c|c|c|c|}
\hline Genotype & 2013 C & $\mathrm{R}$ & 2014 C & $\mathrm{R}$ & 2015 C & $\mathrm{R}$ & $\begin{array}{c}2016 \\
\text { C }\end{array}$ & $\mathrm{R}$ & $\begin{array}{c}2017 \\
\text { C }\end{array}$ & $\mathrm{R}$ & $\begin{array}{c}2018 \\
\text { C }\end{array}$ & $\mathrm{R}$ & Mean & $\operatorname{Rank}(\mathrm{A})$ \\
\hline SAMADA 07 & 20.38 & 4 & 22.85 & 3 & 20.53 & 5 & 22.11 & 3 & 26.23 & 4 & 23.50 & 2 & 22.60 & 3 \\
\hline PR31Y43 & 21.70 & 3 & 23.06 & 2 & 22.08 & 2 & 21.66 & 1 & 24.97 & 2 & 22.84 & 3 & 22.72 & 2 \\
\hline Burak & 22.15 & 2 & 24.11 & 1 & 20.64 & 4 & 21.66 & 2 & 25.23 & 1 & 25.20 & 1 & 23.17 & 1 \\
\hline DKC7211 & 18.81 & 5 & 20.41 & 5 & 21.46 & 3 & 18.17 & 5 & 24.96 & 3 & 20.66 & 5 & 20.75 & 5 \\
\hline DKC7221 & 22.46 & 1 & 22.66 & 4 & 22.59 & 1 & 19.93 & 4 & 25.20 & 5 & 20.89 & 4 & 22.29 & 4 \\
\hline Mean & 21.10 & & 22.62 & & 21.46 & & 20.71 & & 25.32 & & 22.62 & & & \\
\hline IPCAe1 & 0.345 & & -0.301 & & 1.381 & & 0.660 & & 0.404 & & -1.168 & & & \\
\hline IPCAe2 & -1.098 & & -0.418 & & 0.163 & & 0.106 & & 0.989 & & 0.258 & & & \\
\hline IPCAe3 & 0.287 & & 0.242 & & -0.142 & & -0.216 & & 0.188 & & 0.282 & & & \\
\hline IPCAe4 & 0.014 & & 0.188 & & -0.042 & & 0.074 & & 0.074 & & -0.278 & & & \\
\hline
\end{tabular}

Table 7. Mean dry matter yield ( $\mathrm{t} \mathrm{ha} \mathrm{a}^{-1}$ ) of maize hybrids, environments, and the results of principal component analysis for the tested hybrids

\begin{tabular}{|c|c|c|c|c|c|c|c|c|c|c|}
\hline \multirow[b]{2}{*}{ Genotype } & \multicolumn{10}{|c|}{ YSI (Yield stability index) parameters } \\
\hline & Mean & $\begin{array}{l}\text { RANK } \\
\text { (A) }\end{array}$ & IPCA1 & IPCA2 & IPCA3 & IPCA4 & ASV & $\begin{array}{l}\text { ASV rank } \\
\text { (B) }\end{array}$ & $\begin{array}{l}\text { YSI (A + } \\
\text { B) }\end{array}$ & $\begin{array}{l}\text { YSI } \\
\text { rank }\end{array}$ \\
\hline SAMADA 07 & 22.60 & 3 & 0.367 & 0.426 & 0.617 & -0.271 & 0.85 & 3 & 6 & 3 \\
\hline PR31Y43 & 22.72 & 2 & 0.061 & -0.274 & -0.038 & -0.972 & 0.30 & 1 & 3 & 1 \\
\hline Burak & 23.17 & 1 & 0.505 & -0.051 & -0.655 & -0.348 & 1.01 & 4 & 5 & 2 \\
\hline DKC7211 & 20.75 & 5 & -0.713 & 0.277 & -0.045 & -0.045 & 1.44 & 5 & 10 & 4 \\
\hline DKC7221 & 22.29 & 4 & -0.221 & -0.378 & 0.688 & 0.468 & 0.58 & 2 & 6 & 3 \\
\hline
\end{tabular}

Table 8. The stability values of five maize genotypes in different environments for dry matter yield (t ha $\left.{ }^{-1}\right)$

\begin{tabular}{lccccc}
\hline Genotype & Mean & $\begin{array}{c}\text { Determination of } \\
\text { coefficient }\end{array}$ & $\begin{array}{c}\text { Regression } \\
\text { coefficient }\end{array}$ & $\begin{array}{c}\text { Deviation from the mean } \\
\text { square regression }\end{array}$ & $\begin{array}{c}\text { Regression } \\
\text { line } \\
\text { intercept }\end{array}$ \\
\hline SAMADA 07 & 22.6 & $\mathrm{R}^{2}$ & $\mathrm{bi}$ & $\mathrm{S}$ di & $\mathrm{a}$ \\
PR31Y43 & 22.7 & 0.83 & 1.18 & 4.042 & -3.702 \\
Burak & 23.2 & 0.99 & 0.84 & 0.055 & 6.173 \\
DKC7211 & 20.7 & 0.63 & 0.92 & 4.062 & 2.587 \\
DKC7221 & 22.3 & 0.84 & 1.32 & 7.541 & -8.627 \\
Confidence interval & $-\mathrm{x}= \pm 0.74$ & 0.61 & 0.84 & 6.367 & 3.568 \\
\hline
\end{tabular}

\subsection{Stability index for dry matter yield}

The regression coefficient (bi) of maize genotypes ranged from 0.84 to 1.32 , the deviation from mean square regression ranged from 0.055 to 7.062 , regression line intercept (a) constant was between 2.587 and 8.627. The PR31Y43 and Burak genotypes had a high stability, while the stability of SAMADA07, DKC7211 and DKC7211 genotypes were low. The PR31Y43 and Burak hybrid provided medium efficiency in medium stability. The DKC7211, DKC7221 and SAMADA07 maize hybrids were determined as low stabile (Table 8, Figure 18 and 19).

\section{Conclusions}

The resultsAMMI and GGE biplot analysis on herbage yield and dry matter yield of five different hybrids in a six-year experiment indicated that a significant variation for the stability of genotypes in herbage and dry matter yields. The herbage and dry matter yields fluctuated during the years. The differences can be attributed to the climatic factors (light intensity, temperature, short-term heavy rains, number of days cloudy, etc.) among the years. The joint examination of Biplot models for different stability parameters provided similar results with different stability indexes. In addition, graphical representation was more effective than the intelligibility of numerical figures. The results concluded that PR31Y43 and Burak silage maize hybrids had high stability for the tested years. The priority should be given the two in the adaptation studies at the conditions of farmers. High stability of PR31Y43 and Burak hybrids should be used as standard varieties in breeding studies.

\section{Acknowledgement}

Authors thank the Republic of Turkey Ministry of Agriculture and Forestry, General Directorate of Agricultural Research and Policies for the support provided for this study (Project Number; TAGEM/TA/14/A12/P03/010).

\section{Authors' Contributions}

Erkan Özata: Methodology, Investigation, Conceptualization, Formal analysis, Validation, Writing original draft, Review and editing. 


\section{Conflict of interest}

The authors declare that they have no conflict of interest.

\section{References}

Ahmadi, J., Mohammadi, A., Najafi Mirak, T. (2012). Targeting promising bread wheat (Triticum aestivum L.) lines for cold climate growing environments using AMMI and SREG GGE biplot analyses. Journal Agriculture Science Technology Volume (14), 645-657.

Akçura, M., Taner, S., and Kaya, Y. (2011). Evaluation of bread wheat genotypes under irrigated multienvironment conditions using GGE biplot analyses. Žemdirbystė Agriculture (98), 35-40.

Badu-Apraku, B., Oyekunle, M., Obeng-Antwi, K., Osuman, A.S., Ado, S.G., Coulibay, N., Yallou, C.G., Abdulai, M., Boakyewaa, G.A., and Didjeira, A. (2012). Performance of extra-early maize cultivars based on GGE biplot and AMMI analysis. Journal Agriculture Science (150), 473483.

Bantayehu, M., Esmael, J., and Awoke, Y. (2013). Additive main effect and multiplicati ve interaction analysis and clustering of environments and genotypes in malting barley. African Journal of Agricultural Research Volume 8 (18), 1896-1904.

Dehghani, H., Ebadiand, A., and Yousefi, A. (2006). Biplot analysis of genotype by environment interaction for barley yield in Iran Agronmy Journal (98),388-393.

Dia M., Wehner T.C., Hassell R., Price D.S., Boyhan G.E., Olson S., King S., Davis A.R., Tolla G.E., Bernier J., Juarez B., Sari N., Solmaz I., Aras V. (2012). Stability of fruit yield in watermelon genotypes tested in multiple US environments. University of Cukurova, Ziraat Fakultesi, (4), 84-88.

Eberhart, S. A., and Russell, W. A. (1966). Stability parameters for comparing varieties, Crop Science, (6), 36-40.

Faria, S. V., Luz, L. S., Rodrigues, M. C., Carneiro, J. E. D. S., Carneiro, P. C. S. and De Lima, R. O. (2017). Adaptability and stability in commercial maize hybrids in the southeast of the State of Minas Revista Ciência Agronômica, Volume. 48, (2), 347-357

Farshadfar, E., Mahamodi, N., and Yaghotipoor, A. (2011). AMMI stability value and simultaneous estimation of yield and yield stability in bread wheat (Triticum aestivum L.). Australian Journal of Crop Science, 5 (13), 1837-1844.

Gauch, H.G., and Zobel, R.W. (1997). Identifying megaenvironment and targeting genotypes. Crop Science (7), 381-385.

Gauch, H. G. (2006). Statistical analysis of yield trials by AMMI and GCE. Crop Science (46), 1488-1500.

Gür, İ., and Kara, B., (2019). Trabzon Ekolojik koşullarında atdişi hibrit mısır çeşitlerinin performansları. Black Sea Journal of Agriculture 2 (2), 103-108.

Kendal, E., and Sayar, M. S. (2016). The stability of some spring Triticale genotypes using biplot analysis, The Journal of Animal \& Plant Sciences, 26 (3), 754-765

Kendal, E., and Sener, O. (2015). Examination of genotype environmentinteractionsby GGE biplot analysis in spring durum wheat, Indian Journal of Genetics and Plant Breeding 75 (3), 341-348.
Kendal, E., and Tekdal, S. (2016). Application of AMMI model for evolution spring barley genotypes in MultiEnvironment trials- Bangladesh Journal Botany 45(3), 613-620.

Mortazavian, S. M. M., Nikkhah, H. R., Hassani, F. A., Sharif-al-Hosseini, M., Taheri, M., Mahlooji, M. (2014). GGE biplot and AMMI Analysis of yield performance of barley genotypes across different environments in Iran Journal Agriculture Science Tech.nology Volume (16), 609-622.

Munawar, M., Hammad, G., and Shahbaz, M. (2013). Evaluation of maize (Zea mays L.) hybrids under different environments by GGE Biplot analysis. American-Eurasian Journal Agriculture Environment Science 13 (9),1252-1257.

Muntaz, A., Hussain, D., Saeed, M., Arshad, M., and Yousaf, I, M. (2019). Stability and adaptability of sorghum hybrids elucidated with genotype-environment interaction biplots. Turk Journal Fields Crops 24 (2), 155-163.

Naroui, M.R.R., Kadir, M.A., Rafii, M. Y., Hawa Jaafar, Z. E., Naghavi M. R., and Ahmadi, F. (2013). Genotype $\times$ environment interaction by AMMI and GGE biplot analysis in three consecutive generations of wheat (Triticum aestivum) under normal and drought stress conditions. Australian Journal of Crop Science (7), 956961.

Oliveira, T. R. A., Carvalho, H.W.L., Costa, E. F. N. and Carvalho Filho, J. L. S. (2017). Correlation among adaptability and stability assessment models in maize cultivars. Australian Journal of Crop Science, (11), 516521.

Oliveira, T. R. A. D., Carvalho, H. W. L. D., Oliveira, G. H. F., Costa, E. F. N., Gravina, G. D. A., Santos, R. D. D. and Carvalho Filho, J. L. S. D. (2019). Hybrid maize selection through GGE biplot analysis. Bragantia, Campinas, 78 (2), 166-174.

Öner, F., Aydın, İ., Sezer, İ., Gülümser, A., Özata, E., and Algan, D (2011). Bazı silajlık misır (Zea mays 1.) çeşitlerinde verim ve kalite özelliklerinin belirlenmesi. IX. Tarla Bitkileri Kongresi. 12-15 Eylül 2011. Bursa.

Özata, E., Öz, A., ve Kapar, H. (2012). Silajlık hibrit mısır çeşit adaylarının verim ve kalite özelliklerinin belirlenmesi. Tarım Bilimleri Araştırma Dergisi 5 (1), 37-41.

Parent, B., Bonneau, J., Maphosa, L., Kovalchuk, A., Langridge, P., Fleury, D. (2017). Quantifying Wheat Sensitivities to Environmental Constraints to Dissect Genotype $\times$ Environment Interactions in the Field. Plant Physiol (174), 1669-1682.

Purchase, J. L. (1997). Parametric analysis to describe $\mathrm{G} \times \mathrm{E}$ interaction and yield stability in winter wheat. Ph.D. thesis. Dep. of Agronomy, Faculty of Agriculture, Univ. of the Orange Free State, Bloemfontein, South Africa.

Purchase, J.L., Hatting, H., and Vandeventer, C. S. (2000). Genotype $\times$ environment interaction of winter wheat (Triticum aestivum L.) in South Africa: П. Stability analysis of yield performance. South African Journal Plant Soil (17), 101-107. 
Putto, W., Patanothai, A., Jogloy, S. and Hoogenboom, G. (2008). Determination of mega-environments for peanut breeding using the CSM-CROPGRO-Peanut model. Crop Science (48), 973-982.

Rakshit,S., Ganapathy, K.N., Gomashe, S. S., Rathore, A., Ghorade, R. B., Kumar, M. V. N., Ganesmurthy, K., Jain, S. K., Kamtar, M.Y., Sachan, J. S., Ambekar, S.S., Ranwa, B. R., Kanawade, D. G., Balusamy, M., Kadam, D., Sarkar, A., Tonapi V. A. and Patil, J.V. (2012). GGE biplot analysis to evaluate genotype, environment and their interactions in sorghummulti-location data. Euphytica. (185), 465-479.

Rezene, Y. (2014). GGE and AMMI biplot analysis for fieldpea yield stability in SNNPR state Ethiopia. International Journal Sustainable Agriculture Research 1(1), 28-38.

Roostaei, M., Mohammadi, R., and Amri, A. (2014). Rank correlation among different statistical models in ranking of winter wheat genotypes. The Crop Journal, (2), 154163.

Samonte, S.O.P.B., Wilson, L. T., Mc Clung, A. M., and Medley, J. C. (2005). Targeting cultivars onto rice growing environments using AMMI and SREG GGE biplot analyses. Crop Science (45), 2414-2424.

Yan, W. (2001). GGE biplot-a Windows application for graphical analysis of multi-environment trial data and other types of two-way data. Agronomy Journal (93),1111-1118

Yan, W., and Rajcan, I. (2002). Biplot analysis and trait relations of soybean. Crop Science, Volume (42),12-21.

Yan, W. (2002). Singular value partitioning in biplot analysis of multi environment trial data. Agronomy Journal (94), 990-996.

Yan, W., and Kang, M. S. (2003). GGE Biplot Analysis: A Graphical Tool for Breeders, Geneticists, and Agronomists. Boca Raton FL, CRC Press.

Yan, W., and Tinker, N. A. (2006). Biplot analysis of multienvironment trial data: Principles and applications. Canadian Journal of Plant Science (86), 623-645.

Yan, W., Hunt, L.A., Sheng, Q., and Szlavnics, Z. (2000). Cultivar evaluation and mega-environment investigation based on the GGE biplot. Crop Science (40):597-605.

Yan, W., Kang, M. S., Ma, B., Woods, S., and Cornelius, P. L. (2007). GGE biplot vs. AMMI analysis of genotypeby-environment data. Crop Science (47), 643-655.

Yan, W., Cornelius, P. L., Crossa, J. and Hunt, L. A. (2001). Two types of GGE biplots for analyzing multienvironment trial data. Crop Science (41),656-663.

Yan, W. and Frégeau-Reid, J. (2018). Genotype by Yield* Trait (GYT) Biplot: a novel approach for genotype selection based on multiple traits. Scientific Reports, 8(1) $1-10$.

Turkish Journal of Food and Agriculture Sciences is licensed under a Creative Commons Attribution-NonCommercialNoDerivatives 4.0 International License 